\title{
Transferring a Teaching Learning Sequence Between Two Different Educational Contexts : the Case of Greece and Finland
}

\section{Spyrtou, Anna}

2018-02

Spyrtou , A , Lavonen , J , Zoupidis , A , Loukomies , A, Pnevmatikos , D , Juuti , K \& Kariotoglou , P 2018 , ' Transferring a Teaching Learning Sequence Between Two Different Educational Contexts : the Case of Greece and Finland ' , International Journal of Science and Mathematics Education, vol. 16 , no. 3 , pp. 443-463 . https://doi.org/10.1007/s10763-016-9786-y

http://hdl.handle.net/10138/233757

https://doi.org/10.1007/s10763-016-9786-y

acceptedVersion

Downloaded from Helda, University of Helsinki institutional repository.

This is an electronic reprint of the original article.

This reprint may differ from the original in pagination and typographic detail.

Please cite the original version. 
Spyrtou, A., Lavonen, J. M. J., Zoupidis, A., Loukomies, A. M., Pnevmatikos, D., Juuti, K. P. T. \& Kariotoglou, P. (2016). Transferring a Teaching Learning Sequence Between Two Different Educational Contexts: the Case of Greece and Finland. International J ournal of Science and Mathematics Education, 1-21. https://doi.org/10.1007/s10763-016-9786-y

\section{Transferring a Teaching Learning Sequence Between two Different Educational \\ Contexts: the Case of Greece and Finland}

ABSTRACT. In the present paper, we report on the idea of exchanging educational innovations across European countries aiming to shed light on the following question: how feasible and useful is it to transfer an innovation across different national educational settings? The innovation, in this case, Inquiry-Based Teaching Learning Sequences, is recognized as a crucial component of renewal science teaching in European countries. Two local working groups from two different Universities, in Finland and Greece, were created consisting of researchers and experienced primary teachers. The transfer from Greece to Finland was rather challenging because of the differences between the two educational contexts. The initial, as well as the revised Teaching Learning Sequence, were implemented for 11-12-year-old students including the content to be taught, that is Floating-Sinking phenomena and density, and the learning environment aspects such as learning Control of Variables Strategy. A combination of qualitative and quantitative research methods was implemented in order to formulate concrete recommendations on feasible and useful aspect. The feasible aspect adduces answers to the query of "how" this transfer worked in practice. Concerning this aspect, the recognition of what is innovative for each national partner was recognized as a crucial factor for the design and revision of both Teaching Learning Sequences. The useful aspect illuminates students' improvement in the achievement of conceptual as well as procedural knowledge. The results revealed that the psychological paths that bring about this success are ecumenical and independent of the history of the educational group. 
KEYWORDS: control of variables strategy; floating-sinking phenomena; inquiry; TeachingLearning Sequences; transferring educational innovations.

\section{Introduction}

An essential aim of European Union (EU) Framework projects is to design, together with experts from several EU member countries, educational innovations to solve problems in education, such as the lack of students' engagement in science learning and the dearth of scientists. Moreover, these innovations should be adoptable in other education contexts. However, dissemination and adoption are not straightforward processes. For example, the 'European knowledge paradox' concerning the contradiction between "high quality of research in combination with a low degree or speed of knowledge dissemination and uptake" (Enders, 2005, p. 119) is well-known.

In this paper, we highlight this general objective, namely the adoption of a science education innovation in other education context where it has been developed. The innovation, in this case, Inquiry-Based Teaching Learning Sequences (TLSs), is recognized as crucial component of renewal science teaching practices in European countries (EACEA/Eurydice, 2011; EU, 2007).

We designed the innovation in the context of a cross-national curriculum project entitled: University-School partnerships for the development and implementation of researchbased ICT-enhanced TLSs on Materials Properties (Authors \& colleagues, 2010). There was one major challenge to be faced with this project: how to formulate concrete recommendations for the successful transfer of inquiry-based TLSs from one national educational setting to another crossing cultural and organizational barriers. To meet this challenge, two local working groups from two different Universities were created consisting of researchers and experienced primary teachers. The groups designed locally according to 
the guidelines of the project inquiry-based ICT-enhanced TLSs in the area of materials properties, such as everyday applications of paper, plastics, and density and, moreover, implemented and evaluated these TLSs in real classrooms. Furthermore, the groups exchanged their experiences over the three-year period in order to consider the difficulties as well as the educational benefits of this enterprise. In addition, an international steering committee of experts monitored the process and created general guidelines for the design and evaluation of the TLSs.

In this study, we report on the transfer of an Inquiry-Based TLS from Greece to Finland, thereby producing evidence about a crucial educational and policy issue: how feasible and useful it is to transfer an educational innovation across different European educational settings: those existing in Greece and Finland.

\section{Transferring an Innovation}

\section{What Is an Innovation?}

According to Rogers (2003), "An innovation is an idea, practice, or object that is perceived as new by an individual". (p. 12). An innovation may also be something one has known for some time but has not neither developed an attitude towards nor adopted or nor rejected. For example, a teacher who knows about a cooperative learning method but never passed into the (his/her) teaching practice. As entirely new ideas are rare, we also consider a modification of an existing idea to be an innovation for those who are adopting it, e.g. a novel use of an ICT tool can be an innovation to a group of persons who has come up with a new use (Rogers, 2003).

How does innovation get transferred between entities? This question seems to be of great interest of various fields of science since it has been studied by researchers from different fields which focus on "knowledge use" or "knowledge and skills transfer" including 
terms of procedures or outcomes such as "diffusion", "dissemination", "re-invention", "modification", and "adaptation". For instance, in the area of management, a common issue underlies the importance of transferring knowledge effectively from one unit (e.g. individual, group, organization, country) to another in order for it to be more productive and additionally more likely to survive (Darr \& Kurtzberg, 2000; Song et al., 2007). Concerning the field of Tertiary education, the dissemination process of innovations into universities for achieving positive system changes is recognized as a relatively difficult enterprise due to its inherent complexity (Elton 2003). For improving health and health systems, the "Knowledge transfer" process includes carefully designed dissemination activities considering audience needs (Gagnon, 2011).

More perspectives to the discussion about concept "transfer" can be constructed by taking a look at the origins of the word "transfer". In Latin, 'trans' means over, or across the border, and "ferre" means to carry. The notion of carrying (typically knowledge and skills) refers to something which is done actively through employing communication on purpose. The word 'trans' suggests that during the process of carrying, a border is crossed (Autio \& Laamanen, 1995). Accordingly, the transfer can be viewed as an active process, during which knowledge and skills are carried across the border of two entities. These entities -designer of an innovation and adapter of this innovation - could be included countries, organizations, universities, companies, schools, individuals, etc. (Hutchinson \& Huberman, 1994; Goh, 2002; Song et al., 2007; Straus, Tetroe, \& Graham, 2011).

A synthesis of the literature on knowledge transfer is beyond the scope of this paper. Taking into account that our primary goal is to overcome the obstacles concerning the use of an educational innovation in a different educational setting, we decided to use the term "transfer" of innovation to incorporate the connotations of both dissemination and adaption. Therefore, "transfer" is considered as a social process that involves strong interpersonal 
communication relationships among educational stakeholders (researchers, teachers, steering committee members) with the prospect of the innovation being modified and implemented in a new educational setting (Fullan, 2007; Hutchinson \& Huberman, 1994; Rogers, 2003).

What factors influence the transfer? Crossing the border of two entities, namely transferring an innovation, is a particular type of interaction in which the adapters could be modified by the adapters and implemented in the context where the transfer occurs (Fullan 2007). In this paper, we focus on the context in which the innovation is to be implemented: this being one of the main factors affecting whether or not an innovation is transferred effectively (Gagnon, 2011; Hutchinson \& Huberman, 1994).

The transfer of innovation is "an exercise in change" (Elton, 2003) requiring understanding as well as management of change in order to overturn well-rooted traditions. Successful transfer requires strong collaboration development within an open and a trusting atmosphere depending on the local characteristics of the context. In the area of education, local characteristics include teachers' pedagogical orientation, their teaching, and learning beliefs, as well as the leadership and support available to them in school (Fullan, 2007). In addition, the professional level of teachers' pedagogical and subject matter knowledge as well as their professional confidence in mastering an innovation may influence the effectiveness of transfer (Pinto, 2005). Moreover, the education context of the country, e.g. a curriculum, level of accountability policy and school inspection, have an influence to the teachers' decisions considering the adoption of the innovation. For example, heavy testing culture could prevent teachers to apply anything new in their teaching. When a teacher is determining whether to accept or reject an innovation, s/he seeks information about the innovation and actively processes that information, typically with other teachers in his/her school (Rogers, 2003). 
Summarizing, transfer of an educational innovation is regarded as a complex and highly contextualized task. In order to have a clear view of a particular transfer concerning an educational innovation, it is essential to describe and compare the contexts of the two interactive entities. So, in the next subsection, we focus on Finnish and Greek compulsory science education contexts.

\section{Finnish and Greek Compulsory Science Education: two Different Educational Contexts}

In order to have a clear view of the differences as well as the similarities between the two educational settings concerning science education, we took into account international as well as European official documents: PISA (OECD, 2010) and EACEA/Eurydice (2008, 2011) findings respectively. Having as a starting point the characteristics and requirements of the project (i.e. inquiry orientation), we compare Greek and Finnish science education at three levels: (i) students' achievement in science according to PISA findings (OECD, 2010); (ii) recommended science learning activities from steering documents; and (iii) autonomy and responsibility of teachers. Table 1 presents the key features of Finnish and Greek science education corresponding to the levels above.

We see the differences between Finnish and Greek students concerning average science performance in Table 1. Specifically, taking into account that in the EU-27 average science performance was 501.3, Finland was about 50 points higher than the EU-27 average while Greece was about 31 points lower. The average of Finnish student low achievers in science skills is quite small (6\%) in relation to their Greek peers $(25.3 \%)$. We realize that Greece is lagging behind the European policy goal of reducing the proportion of 15-year-olds with low achievement in science to below $15 \%$ by 2020 .

We selected a list of science learning activities from the EACEA/Eurydice document (2011, pg. 72) including those that could be compared -in the next sections- with the related 
activities of the two TLSs. We recognized that the only common key feature between the two countries is the use of ICT in secondary schools. These activities, among others, are considered essential in order to support science competencies and increase students' motivation (EACEA/Eurydice, 2011). Indeed, Authors (2013) analyzed the Finnish primary science curriculum and recognized that it emphasizes science competencies similar to PISA framework, including identifying of scientific issues, planning and implementing of science inquiry; explaining scientific phenomena and use of scientific knowledge in problem-solving and moreover, drawing of evidence-based conclusions. On the contrary, in Greece, related activities such as evaluating and justifying explanations are not recommended in official documents. The Finnish curriculum emphasizes the choice of appropriate teaching and assessment methods conducive to encouraging the feeling of autonomy and competence, by the grouping of students in order to support the sense of relatedness, or through offering students meaningful choices. Therefore, the curriculum takes into account knowledge about factors influencing student motivation. Furthermore, the role of context, like out-of-school learning is emphasized in the curriculum and its impact on the development of interest (Deci \& Ryan, 2004).

Table 1

Key features of Finnish and Greek science education

\begin{tabular}{lcc}
\hline \multicolumn{1}{c}{ Key features } & Finland & Greece \\
\hline KF1: Average Science performance (PISA 2009) & 554 & 470 \\
KF2: Low level of core competencies in science & $6 \%$ & $25.3 \%$ \\
(PISA 2009) & & \\
KF3: Science learning activities & & \\
KF3i: Experiments and explanations & & - \\
- evaluating explanations & $\mathrm{p} / \mathrm{s}$ & - \\
- justifying explanations & $\mathrm{p} / \mathrm{s}$ & - \\
- presenting experiment results & $\mathrm{s} / \mathrm{s}$ & $\mathrm{s}$ \\
KF3ii: Use of specific ICT applications & $\mathrm{s}$ & \\
$\bullet \quad$ Computer simulations & & \\
KF4: Autonomy and responsibility of teachers & & \\
\hline
\end{tabular}


- determining the content of the curriculum S/T autonomy No autonomy

- choice of teaching methods Full autonomy Full autonomy

- choice of school textbooks S/T autonomy No autonomy

Note. $\mathrm{p}=$ primary school; $\mathrm{s}=$ secondary school; $\mathrm{S} / \mathrm{T}=$ school and teachers

However, it is important to stress that the data in line KF3 in Table 1, are derived from steering national level documents, and thus, they may not provide any information on teaching practice reality (EACEA/Eurydice, 2011, p. 71).

In Finland, school and teachers -individually or collectively- determine the content according to the national level core curriculum as well as their choice of school textbooks and other learning materials ( $\mathrm{S} / \mathrm{T}$ autonomy). In Greece, there is no autonomy regarding these two issues. However, in both countries teachers have full autonomy in choosing teaching methods and other additional learning materials. Actually, the well-known cue 'culture of trust' has represented Finnish education policy concerning teachers and school autonomy since the 1990s (Authors, 2009) while Greece has a strongly centralized system in the preparation and delivery of school textbooks, namely, for each subject in each school grade there is a single national textbook (EACEA/Eurydice, 2008).

From the above comparative analysis, we realize that the Finnish educational setting is more supportive for the design and adoption of educational innovations than the Greek since it supports teacher autonomy as well as activities which intended to promote student interest in science. We also recognize the significant difference between the two countries concerning student achievement in the results of PISA.

\section{The Transfer Process Between Different Educational Contexts:}

\section{A Case of Designed-Based Research}

In this paper, the transfer of an educational innovation is discussed in the context of the Designed-Based Research which has been used as an approach to design the TLSs. One of the 
discernible characteristics of this approach is its own gradual research-based evolutionary process; a process of cycles of invention and revision based on the systematic study of evidence from one TLS implementation to another (Lijnse, 1995; Cobb et al., 2003). The importance of Designed-Based Research lies in making explicit its own iterative design, underlining the refinements between two TLSs' consecutive implementations; the intended outcome is the construction of a particular theoretical framework that supports "teachers' real work" in designing TLSs. The "teachers' real work" includes specific theoretical tools that can be applied in relevant situations (Cobb et al., 2003; Tiberghien, Vince \& Gaidoz, 2009). Consequently, in this study, we aim to highlight the idea of supporting "real work" in transferring a TLS between two different educational contexts.

Especially, the partners of each local group cooperated in a reinforced atmosphere of interaction so as to modify and furthermore adapt the first innovation into the reality of each country's classroom (Fullan, 2007; Hutchinson \& Huberman, 1994). This close cooperation is based on a perspective that teachers are active constructors -and not passive agents- in the transfer of TLS innovation from one context to another. Teachers need time to reflect on the innovative characteristics of the TLS, to share and combine ideas and suggestions, synthesize, add or revise teaching-learning materials and methods and, furthermore, revise their beliefs (Fullan, 2007).

Furthermore, the iterative design process of Designed-Based Research produces plenty of data acquiring credible information about learning outcomes in specific contexts (Authors \& colleagues, 2016).

\section{Method}

\section{Research Design}

In line with the above consideration, initially, the Greek group (1) carried out a developmental phase including the design, development, implementation and evaluation of an 
innovative $\mathrm{TLS}_{1}$ for its own country (educational context 1), to create a revised $\mathrm{TLS}_{2}$ (Authors \& colleagues, 2016). Afterwards the process of transfer included the following steps (Fig. 1): (a) the Finnish group (2) observed the implementation of the $\mathrm{TLS}_{2}$ in the educational context 1 and discussed with the Greek group the design principles as well as the content and pedagogy approach; and (b) the group (2) produced the TLS 3 , that is a revised version of the $\mathrm{TLS}_{2}$, taking into account the educational context 2 of its own country. Finally, the group (2) organized partial trials to finalize the $\mathrm{TLS}_{3}$ for the new context.

In order to evaluate this transfer process, we seek to analyze: (i) the characteristics of the two TLSs and (ii) the learning outcomes of Greek and Finnish students involved in this enterprise. So, the research questions are:

I. Which were the characteristics of the initial as well as the revised TLS?

Ia. Which were the innovative characteristics of each TLS?

Ib. Which were the revisions from the TLS 2 to $\mathrm{TLS}_{3}$ ?

II. Do the learning outcomes differ between Greek and Finnish students, after the implementation of the TLSs?

IIa. How do students' interpretations concerning Floating - Sinking phenomena evolve, before and after the implementation of the TLSs?

IIb. How does the students' learning of Control of Variables Strategy evolve, before and after the implementation of the TLSs? 


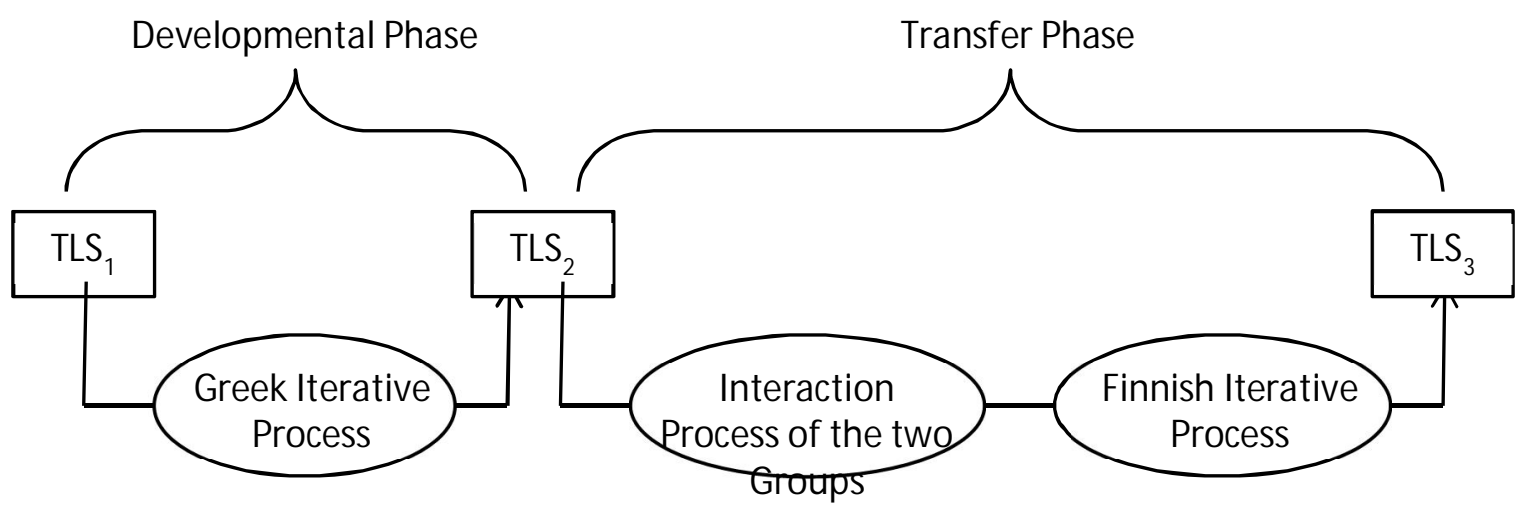

Figure 1. The sequential order of the two partners' cooperation

The TLSs were designed and developed for $(11-12)$ year old students, 41 Greek, and 21 Finnish. In both countries, we selected two public schools in urban areas attended by students of the middle socio-economical class.

Data Collection and Analysis: First Research Question. In order to answer the first research question, we compare four booklets produced in the project as the final deliverables with the national curriculum of two countries concerning related science content.

The four booklets include two types of project outcomes: (i) the "Teacher's Manual" and (ii) the students' worksheets named “Teaching-Learning Activities”. It was decided to select these two booklets as raw data sources because they were designed in very close cooperation between the two local groups. Moreover, interviews, video recorded lessons, and researchers' discussions with steering committee experts were considered as raw data. The "Teacher's Manual" comprises the rationale of the TLSs, the content to be taught -FloatingSinking (FS) phenomena and density-, the learning environment aspects (e.g. learning Control of Variables Strategy (CVS), ICT use), students' difficulties concerning the content, and the relevant literature. The "Teaching-Learning Activities" includes analytically all the students' activities with the related worksheets.

Following a directed content analysis, we used the specific guidelines of the project in order to define the thematic units of book content (Hsieh \& Shanon, 2005). Concretely, 
according to the project, the four common features of all the Inquiry-Based TLSs should be the following: (i) the study of the fundamental properties of materials, (ii) the inquiry approach to learning, (iii) the use of models and modeling activities, and (iv) the use of ICT to facilitate inquiry learning. These four features correspond to the thematic units in our data analysis; namely, we immediately begin coding with them as predetermined codes (Hsieh \& Shanon, 2005).

Taking into account the four thematic units, we analyzed the booklet content, studying: (i) if these characteristics are innovative for the two educational contexts (Greek and Finnish); and (ii) the detailed refinements from the initial to the revised TLS. This comparative analysis was implemented in two phases. Firstly, two experts from each group isolated the elements of the resources that were considered to be informative for the aims of the current study. That is, two experts of each Local Working Group separately analyzed the data of its own TLS booklets and compared these characteristics to their own national curriculum. If a characteristic does not exist in the national curriculum or in textbooks is recognized as innovative. Inter-rater agreement between the experts in each group was high (80-90\% original agreement). After the discussion, the agreement increased to $100 \%$. Then, one expert of each group rated the elements of the other group, and his/her results were crosscompared to the ratings of the other group. The inter-rater agreement was once again high $(91-95 \%)$ and after a discussion the inter-rater agreement reached $100 \%$.

Data collection and analysis: second research question. It was decided that the second research question would be answered by using students' answers in pre and post questionnaire tasks that assess both conceptual (research question IIa) and procedural knowledge (research question IIb). The questionnaire was translated from English to both Greek and Finnish. The tasks that were used are introduced in Table 2. 
The aim of the first tasks was to record students' interpretations concerning FS phenomena in everyday life. Task 1 was inspired by Havu-Nuutinen (2005) and, due to the students' age, the researchers modified the task according to the scenario of the implementation. Havu's study subjects were six years old pre-schoolers while in this study the students were $5^{\text {th }}$ graders. Tasks 2 and 3 were inspired by Author and colleagues (2003) and were also modified by the researchers to be suitable for the specific research students' age range.

Specifically, the first task examines the explanations that the students give concerning (a) floating of the life buoy (task 1a) and (b) sinking of the anchor (task 1b) phenomena. Task 2 examines if the students have the idea, about FS, that a big object will sink, and a small will float. The $2^{\text {nd }}$ icon - option in this task gives the students the opportunity to choose the swinging of an object as another situation, apart from the floating or sinking. Task 3 examines if the students have the idea about FS that the width of the vessel influences the phenomenon. The $3^{\text {rd }}$ icon gives the students the opportunity to choose the swinging of an object as another situation apart from the floating or sinking.

Table 2

Tasks for assessing students' explanations about conceptual knowledge

Task On a big ship, among others, you can find: (a) a life-buoy and (b) an 1 anchor. Which of them do you think will float and which will sink if we drop them into the sea? Justify your answer.

Task Costas drops a small piece of a material into a vessel filled with water,

2 and he observes that it floats. Afterward, Irene drops a big piece of the same material into the same vessel. In your opinion, where will the big piece stop moving? Check which number 1,2 or 3 in the picture you think represents the final position of the two bodies that Costas and Irene dropped into the vessel. Justify your choice.

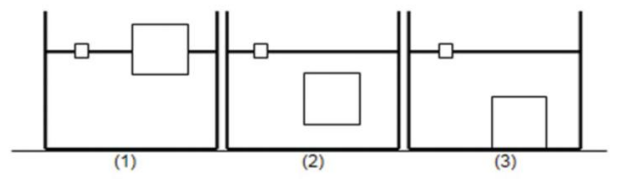


Task Costas dropped the cube into the liquid which is in the wide vessel

3 showed below, and the cube floated. Irene dropped the same cube into a narrow vessel containing the same liquid. In your opinion, where will the cube stop moving in the narrow vessel? Check which number 1,2 or 3 in the picture you think represents the final position of the cube that Irene dropped into the narrow vessel. Justify your choice.



The expected learning outcome in each of these four tasks is that students interpret FS phenomena of an object comparing the density of the object with the density of the liquid. Possible reference to the material of the object is related to the direction of the expected learning outcome.

The assessment of the procedural knowledge is carried out with two tasks (Table 3). Both tasks were inspired by Chen \& Klahr (1999) and Boudreaux et al. (2008) and modified by the researchers for the specific research students' age range. Specifically, tasks 4 and 5 examine to what extent the students learn the control of variables strategy. Students should describe: (a) the procedure to control a variable, and (b) the procedure to draw a conclusion taking into consideration the results of the experiment; in other words, their observations. Task 4 includes a variable negotiated during the implementation of the TLS (the kind of liquid) while task 5 concerns the type of surface of the object, a variable not negotiated during the implementation.

Table 3

Tasks for assessing students' explanations about procedural knowledge

Task 4 George said that «...the kind of liquid in a vessel affects the floating or sinking of a body in this liquid...», whereas Maria said the opposite, that is, «...the floating or sinking of a body in this liquid is independent of the kind of liquid in the vessel...». (a) If you want to find out which of the two students is right, what would you do to check their opinions? (b) If you were to make 
any of your above suggestions, you would draw some conclusion. Describe how you would come to this conclusion.

Task 5 A group of children discuss the factors that can influence the floating and sinking of an object in a liquid placed inside a vessel. One of them says that it is probably influenced by the kind of surface of the object: rough or smooth. This means, more specifically, whether the object has protrusions or not. (a) Can you describe what you would do to check it? (b) If you realized the above proposals, you would have come to a conclusion. Describe the steps in the thought process you would follow in order to reach a safe conclusion.

We analyzed students' answers to all five tasks in order to create answer categories. The categories were created using a bottom - up approach (Strauss \& Corbin 1994), taking into account, on the one hand, the respective scientific view and, on the other hand, the students' respective ideas found in the relevant literature. Specifically, concerning tasks (1-3) we recognize four categories coding from (0: teleological or no answer) to (3: scientifically accepted answer). Specifically, category 3 corresponds to a scientific view, namely, students compare object and water densities in order to interpret the flotation or the sinking of an object in the water. Category 2 includes explanations in which students focus on the material or both to the weight and the material of the object, e.g., "The anchor sinks because it is made of iron, and it is heavy" (task 1b). Category 1 is the basic alternative idea in interpreting FS phenomena, that is, the heavy objects sink and the light ones float. Category 0 includes all the teleological as well as vague or no answers. Thus, the higher score indicates better conceptual understanding and the distance between the categories is theoretically equal, allowing us to calculate mean scores for within participants and between groups comparisons.

Table 4

Categories of students' answers concerning declarative knowledge

\begin{tabular}{ll}
\hline \multicolumn{1}{c}{ Name of Category } & \multicolumn{1}{c}{ Corresponding answers } \\
\hline 3: Density's comparison & "It floats because it has less density than the \\
& water" (task1b) \\
2: Reference to material or & "Well, the bigger piece will float because the \\
both to weight and material & smaller one of the same material floats" (task 2). \\
1: Reference to the weight & "The anchor is sinking because it is heavy." \\
\hline
\end{tabular}


0: Teleological or no answer "The life buoy floats in order to save people."

In Table 4, we present the names of categories as well as examples of the corresponding answers for each category. The analysis in each case (Greece, Finland) was performed by two independent reviewers, with $80-90 \%$ original agreement which, after discussion, increased to $100 \%$. Furthermore, there was a discussion between members of both research groups with minimal disagreements which were eventually resolved.

A similar procedure was followed in other tasks (4-5) as well. In Table 5, we present the name of categories as well as corresponding characteristics of answers for each category in relation to the procedural knowledge to (a) control a variable and (b) draw a conclusion.

In category 3 , the students refer to the steps of the method of controlling if a variable influences a phenomenon, namely, one variable is changed, at least, two trials are implemented, and all other variables are constant (column 2). Some students refer to the need to make observations. Some others refer to their opinion in parallel with describing the method, even if this is not requested. In the same category, we admit students' answers which compare the results of the experiment to draw a conclusion (column 3).

Table 5

Categories of students' answers concerning the procedural knowledge

\begin{tabular}{|c|c|c|}
\hline Name of category & \multicolumn{2}{|c|}{ Characteristics of answers } \\
\hline & Control of variable & Draw a conclusion \\
\hline $\begin{array}{l}\text { 3: Correct description of } \\
\text { CVS }\end{array}$ & $\begin{array}{l}\text { Two trials, all other } \\
\text { variables are constant, } \\
\text { making observations, } \\
\text { or/and refer their opinion }\end{array}$ & $\begin{array}{c}\text { Comparison of the results } \\
\text { of the experiment }\end{array}$ \\
\hline $\begin{array}{l}\text { 2: Partially correct } \\
\text { description of CVS }\end{array}$ & $\begin{array}{l}\text { Refer to the need of an } \\
\text { experiment, or to a } \\
\text { confounded experiment }\end{array}$ & $\begin{array}{c}\text { Mention of the evaluation } \\
\text { of the results of the } \\
\text { experiment }\end{array}$ \\
\hline 1: Inference & $\begin{array}{l}\text { Expression of the inference } \\
\text { instead of the CVS }\end{array}$ & $\begin{array}{c}\text { Expression of the } \\
\text { inference instead of the } \\
\text { CVS }\end{array}$ \\
\hline $\begin{array}{l}\text { 0: No or incoherent } \\
\text { answer }\end{array}$ & $\begin{array}{c}\text { Incoherent, vague or no } \\
\text { description }\end{array}$ & $\begin{array}{l}\text { Mention the procedure of } \\
\text { control of variable, or the }\end{array}$ \\
\hline
\end{tabular}


need for an experiment, incoherent vague or no description

Category 2 contains students' proposals to change and control two variables at the same time as well as the need for one trial instead of two. Moreover, their suggestions about drawing a conclusion are limited to the idea of evaluating the results of the experiment (column 3).

Category 1 comprises an important difficulty that students confront when they are asked to describe how to control a variable or to draw a conclusion: they confuse their own expectations with evidence. Specifically, they just write down their opinion instead of describing the process of controlling the variable or how they drew the conclusion. Finally, in category 0 , we include all the incoherent, vague and no answers. Additionally, in the case of drawing a conclusion, we set mentions about the procedure of control of a variable or the need for an experiment (column 3).

\section{Results}

\section{The Innovative Characteristics of the Two TLSs}

The aim was to teach them the concept of density as a property of materials with the help of FS phenomena. Density was approached in a qualitative way with the "dot crowdedness" model (Smith, Snir, \& Grosslight, 1992) instead of the quantitative approach of the mathematical ratio (Figure 2).

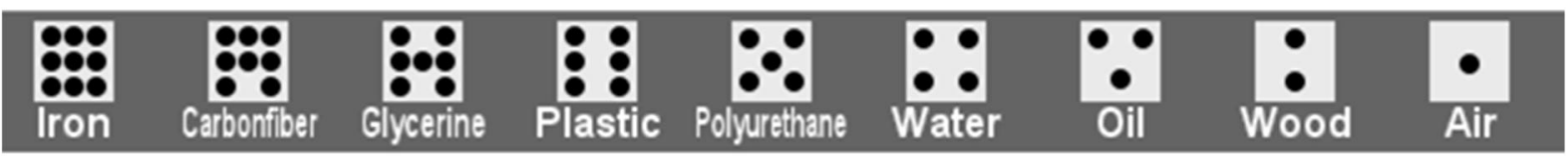

Figure 2. The visual dot crowdedness model of several materials

Considering density as "dots-per-square", it was intended that causal relational reasoning for predicting and explaining FS (Perkins \& Grotzer, 2005) would be achieved: if the density of an object is smaller than water density, then the object will float in the water, and if an object's density is greater than water density, then the object will sink in the water (Authors 
et al., 2008). In Greece, FS phenomena are not included in primary school textbooks, while density is introduced in the $5^{\text {th }}$ grade as a property of materials. In Finland density and FS phenomena as content topics are absent from the curriculum of primary schools. However, they can be taught under the physics and chemistry subtheme "Substances around us" or introduced by making observations about materials around us. Furthermore, the developed teaching TLS is very much according to the learning of procedural knowledge and science process skills, like planning and conducting of experiments, controlling variables and making of evidence-based conclusions. It also dovetails with the cross-curricular themes "Technology and the individual" and "Safety and traffic". So we realize that the introduction of density in the context of FS phenomena to primary school was an educational innovation for both countries (Table 6). The implementation of inquiry activities such as testing which variables affect a phenomenon, conducting an experimental task, presenting results and making conclusions, characterizes the reality of Finnish schools (Authors, 2013). In Greece, related activities are not recommended in official documents, e.g. evaluating explanations (Table 1).

\section{Table 6}

The innovative characteristics of the Teaching-Learning Sequences

\begin{tabular}{lcc}
\hline & $\begin{array}{c}\text { Greek Educational } \\
\text { Setting }\end{array}$ & $\begin{array}{c}\text { Finnish Educational } \\
\text { Setting }\end{array}$ \\
\hline Density \& FS phenomena & IN & IN \\
Inquiry learning environment & IN & No \\
Models \& modeling & IN & IN \\
Use of ICT & IN & IN \\
\hline
\end{tabular}

Note. $\mathrm{IN}=$ Innovative characteristic, $\mathrm{No}=$ no innovative characteristic

On the contrary, primary science textbooks and the teacher's manual support the implementation of a guided inquiry approach through the following steps: brainstorming, hypothesis, experiment, observation, verification or rejection of the hypothesis, drawing a conclusion, and generalization. However, the majority of teachers implement traditional 
deductive teaching-learning practices, followed by experiment demonstrations, while group experimental work is rare. An inquiry learning environment, whenever it exists, is confined to some cross-thematic approaches in two-hour flexible zones of the weekly program which are sporadic and, although encouraged by the official curriculum, the means and motivation are completely lacking for them to be undertaken. As a result of this, the introduction of inquiry activities was an educational innovation only for the Greek TLS.

The $\mathrm{TLS}_{2}$ adapted the argumentations of research that models could facilitate conceptual understanding due to their impact on the development of metaconceptual awareness, metacognitive skills and intentional learning (Vosniadou, 2010). The use of models is particularly effective when the phenomena and the concepts we wish to study are either abstract or not observable (as in the case of density), or they can easily be intelligible by the use of analogies (as in the salvaging of a ship) (Matthews, 2007). With this in mind, $\mathrm{TLS}_{2}$ includes activities related to the nature and role of models, i.e., that models are representations of reality and not its copy, and their primary function is to explain and predict (Treagust et al., 2002). Furthermore, acts of modeling, such as learning and using models, were developed (Justi \& Gilbert, 2002); specifically, the visual model of density was the main tool for acquiring the causal relational reasoning for FS phenomena of homogeneous objects (Fig. 2 and 3). The negotiation of models and modeling was the second common innovation of the two countries since it is not included in the curriculum and textbooks of primary school. 


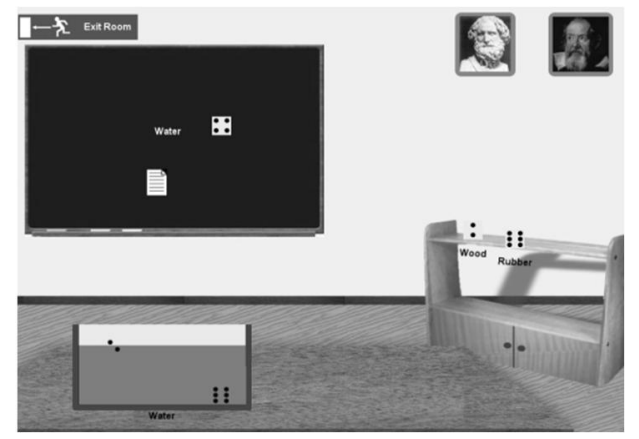

Figure 3. A screenshot of the simulated task for understanding causal relational reasoning

Apart from real experiments, a semi-open software was developed in order to support the understanding of variables affecting FS phenomena as well as the usefulness of the "dot crowdedness" model. The software constituted a single program for Microsoft Windows, making use of Game Maker software including 11 "lab-rooms" (Authors \& colleagues, 2010). For example, students had the opportunity to consider the causal relational reasoning for predicting and explaining FS of wood and rubber (Fig. 3). As we have already discussed in a previous section (2.2), in both countries the use of ICT is not officially recommended for science learning activities for primary school (Table 1). So, the introduction of ICT in the TLS was considered as the third common innovative characteristic in both the Greek and Finnish educational settings.

The revisions of the original and adapted TLS. Systematic cooperation between the researchers and a primary teacher in the Greek group was developed in order to recognize the difficulties in introducing the four innovative characteristics of the TLS. This group had to address students' inexperience of the ICT-based inquiry learning environment. So, they decided to dedicate as much time as possible to implementing the TLS $_{2}$ taking advantage of the flexible zone in the school program. In addition, the primary teacher asked for detailed instructions from researchers to ensure she would implement the designed TLS correctly. In Table 7, we summarize the content and activities included in two versions of the TLS. 
As possible factors affecting FS phenomena were examined analytically using real and software tasks. Density was approached as a property of materials with the use / utilization of the dot crowdedness model in order to predict and explain FS phenomena (see subsection 4.1). An inquiry method, the Control of Variables Strategy (CVS) was used in $\mathrm{TLS}_{2}$ to test whether or not a variable influences FS phenomena (Boudreaux et al., 2008). The taught CVS included three steps: (a) to keep constant all the other variables except for the tested variable, e.g. kind of liquid, (b) to experiment at least twice in order to compare the results, and (c) to draw a conclusion according to the observations. An in-depth analysis from Greek researchers and the primary teacher was developed in order to pinpoint the difficulties in introducing CVS to students. So, taking into account the limited experience of Greek students concerning CVS, a four step-by-step scaffolding approach of CVS was adapted in the TLS 2 (Authors et al., 2008). The first stage of "guided inquiry" consisted of a teacher-controlled activity through which students were directed to test a variable, following the CVS. The second step of "guided inquiry" consisted of a teacher-directed student inquiry in which students carried out an experiment to test another variable, following the same method. The third step of "open inquiry" consisted of a student inquiry experiment to test a variable that was posed by the teacher. Students were expected to design and conduct the experiment. Last, the fourth step of "open inquiry" involved students in designing inquiry experiments to test two variables that are posed by the teacher.

Table 7

Content and activities of the initial and revised Teaching-Learning versions

\begin{tabular}{|c|c|c|}
\hline Content and activities & $\mathrm{TLS}_{2}$ & $\mathrm{TLS}_{3}$ \\
\hline FS phenomena & & \\
\hline - Factors affecting the FS & S & د \\
\hline Density & 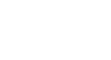 & \\
\hline - a property of materials & د & د \\
\hline $\begin{array}{l}-\quad \text { a criterion for FS of compact and compound objects } \\
\text { Inquiry activities } \\
-\quad \text { scaffolding Inquiry learning }\end{array}$ & د, & , \\
\hline
\end{tabular}


- open Inquiry learning

Models and modeling activities

- aspects of the nature and role of models

- use of the dot model as a representation of density

Use of ICT

Note. TLS $_{2}=$ The Greek TLS version, TLS $_{3}=$ The Finnish TLS version

A similar in-depth and analytical discussion was developed in order to help students understand models and modeling (Authors et al., 2008). TLS 2 followed a gradual approach to the related content, moving from physical models like a ship made of iron representation (Fig. 4a), to symbolic models like the visual model of density, discussing the idea that models serve as tools to predict and explain a phenomenon, describing the nature of models e.g. we can have a variety of visual models for the same property, for instance, density (Fig. 4b).

The Finnish group decided to find a balance between the guidelines of the project and the autonomy of the primary teacher who was completely responsible for adapting the TLS 2 in the Finnish educational context (Table 1). So, due to the students' experience of inquiry learning, all the guided activities and questions were transformed by the primary teacher in an open mode. The decision about what to retain needed to be strict because of time restraints. He estimated that it was not feasible for the introduction of models and modeling to be introduced. He focused only on the use of the density dot model for students to learn how to use it for predicting and explaining FS phenomena. In summary, the revised $\mathrm{TLS}_{3}$ included all the initial tasks (real and software experiments) concerning FS phenomena and density; it had an open inquiry orientation as well as a limited utilization of the content of models and modeling. As a result, the $\mathrm{TLS}_{3}$ consisted of three units (6 hours) while the initial $\mathrm{TLS}_{2}$ had five (10 hours). 


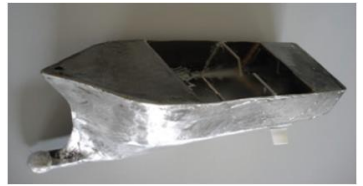

a



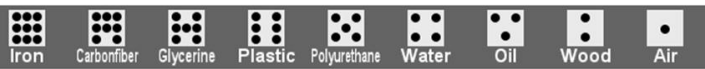

b

Figure 4. Different modes of models: physical and different visual models of density

\section{Students' Learning Outcomes}

A mean score for each task was calculated for each national group separately for pre and post-TLSs' intervention. Means and standard deviations are presented in Table 8.

A series of mixed design repeated measures ANOVA were implemented in our data by national group (Greek versus Finnish) as between participants and measurement time (pre versus post) of the means of each task as within-participant measurement. As Maughly's test indicated that the assumption of sphericity had been violated, the degrees of freedom were corrected using Greenhouse \& Geisser (1959) estimate of sphericity.

In general, the analyses showed significant within-participants main effects.

Participants improved their procedural and conceptual knowledge in most of the measurements. More specifically, participants significantly improved in the conceptual understanding of the buoy task, $F_{(1.00,60.00)=12.43, p=.001,} \eta_{p}{ }^{2}=.17$, the anchor task, $F_{(1.00}$, $60.00)=32.16, p<.001, \eta_{p}{ }^{2}=.35$, and in the big/small task $F_{(1.00,60.00)}=19.15, p<.001, \eta_{p}{ }^{2}=.24$, while the improvement did not significantly differ between the two groups (all $p \mathrm{~s}>.05$ ). However, in the Wide/Narrow task only the interaction between the two groups was significant, $F_{(1.00,60.00)}=8.14, p=.006, \eta_{p}{ }^{2}=.12$. The Greek participants significantly improved in their conceptual understanding of this dimension $(t(40)=3.067, p=.004, d=0.638)$ after the intervention, while the Finnish group, not even significantly, decreased their scores after the intervention $(t(20)=1.307, p=.206, d=0.425)$. 
Table 8

Students' learning outcomes concerning conceptual and procedural knowledge

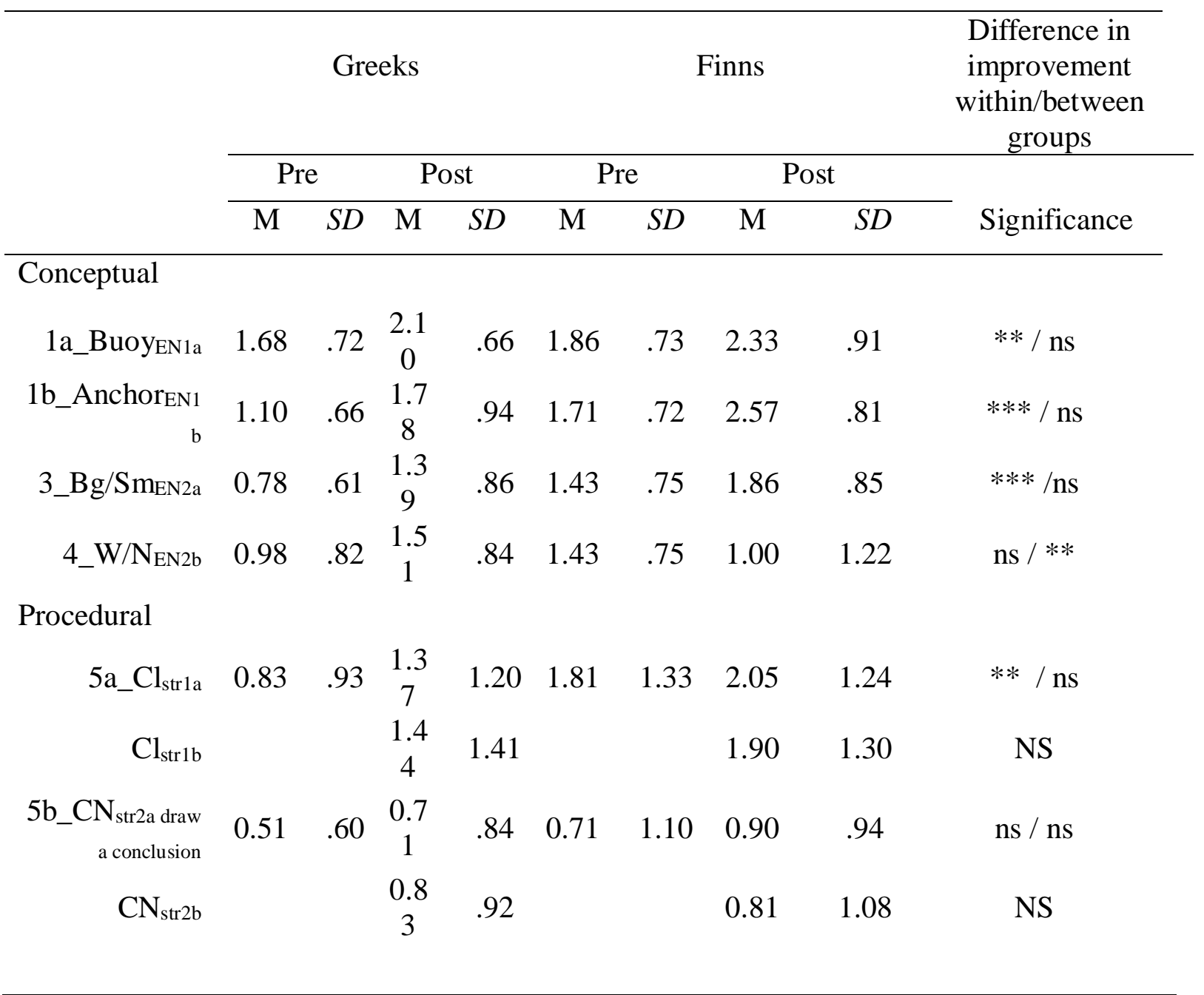

Note: $* * \mathrm{p}<.05, * * * \mathrm{p}<.001, \mathrm{NS}$ and $\mathrm{ns}$ not significant from One-way and repeated measures ANOVAs.

The lower mean with higher standard deviation after the intervention in the Finnish group denotes that some participants were confused after the implementation and scored lower than initially while some others improved their scores. Indeed, non-parametric Sign tests showed that 12 out of $21(57.14 \%)$ Finnish participants scored lower after the intervention, and eight out of 21 increased their scores $(p=.503)$. This was not the case for the Greek participants, only six out of 41 of whom (14.6\%) scored lower after the intervention than before $(z=2.55, p=.011)$. 
Additionally, a significant improvement was achieved after the intervention in the Control of Variables negotiation, $F_{(1.00,60.00)}=9.61, p=.003, \eta_{p}{ }^{2}=.14$. This improvement did not differ between the two groups, $F_{(1.00,60.00)}=1.43, p=.237, \eta_{p}{ }^{2}=.023$. However, only a few participants solved the Draw a conclusion task. There is no significant difference between what the two groups obtained, $F_{(1.00,60.00)}=2.60, p=.112, \eta_{p}{ }^{2}=.042$, for both groups $(p=.985)$.

The previous analyses showed that in general both groups improved their conceptual, and procedural achievements after the intervention and these improvements were going in the same direction. In order to see whether the two groups had the same starting point, a series of One-Way ANOVAs were applied to our data. As expected, the analyses showed that Finnish participants before the intervention scored significantly higher on most tasks examined in the study. More specifically, the Finnish participants performed greater than Greeks in the Anchor task, $F_{(1,61)}=11.361, p=.001$, in the Big/Small task, $F_{(1,61)}=13.374, p=.001$, in the Wide/Narrow task, $F_{(1,61)}=4.485, p=.038$, but not in the Buoy task, $F_{(1,61)}=.804, p=.373$. In the procedural tasks, the Finns initially performed higher than the Greeks in the negotiated CVS task, $F_{(1,61)}=9.272, p=.003$ but not in the Draw a conclusion task, $F_{(1,61)}=.883, p=.351$.

After the intervention, the difference in conceptual and procedural understanding between the two groups diminished and in some measurements it even disappeared. One-way ANOVAs showed that after the intervention a significant difference in the Wide/Narrow task no longer existed, $F_{(1,61)}=3.753, p=0.57$, while in the Big/Small task the initial difference between the two groups diminished. Moreover, the difference between the two groups became very low, $F_{(1,61)}=4.098, p=.047$. The difference between the two groups in the procedural negotiated CVS task also diminished to the level of .05, $F_{(1,61)}=4.479, p=.038$. Additionally, where the two groups did not differ initially, no difference was apparent; $F_{(1,61)}=1.351, p=.250$, and $F_{(1,61)}=.702, p=.406$ both for the Buoy task and the Draw a conclusion task respectively. 


\section{Conclusions-Discussion}

According to the Lisbon Agenda (2000), the idea of exchanging educational innovations across European countries is a strategic objective for achieving sustainable learning environments in the twenty-first century throughout Europe (Alexandrou, Field, \& Mitchell, 2005). In this paper, from the spectrum of exchanging educational innovations, we focused on the transfer of an inquiry-based TLS from Greece to Finland through versatile communication and flexible adoption of the core ideas. The transfer was challenging because of the differences between the Finnish and Greek education contexts.

In our research, we conceptualized the transfer of an educational innovation as a process of invention and revision based on the detailed analysis of the two educational contexts (subsection 3.1). So, in line with the demand that this kind of analysis is intended to construct a particular theoretical framework that supports the relevant transfer of innovations, we decided to use a combination of qualitative and quantitative research methods in order to answer the question: how feasible and useful is it to transfer an innovation across different national educational settings?

In detail, following a qualitative method, we focused on the characteristics of the two implemented TLSs, and specifically on two subcategories: the innovative and the revisions (Fig. 5, feasible aspect). The first rectangle of feasible aspect corresponds to the connotation of "real work" and especially to the question of "how" this transfer worked in practice (see section 2.3). The second rectangle adduces answers related to the useful aspect of the transfer and mainly the important issue concerning students' improvement at two levels that is the achievement of conceptual as well as procedural knowledge. We regard this combination of aspects -feasible and useful- as a framework for transferring an innovation across two different national educational settings (Fig. 5). 
Feasible aspect



Useful aspect

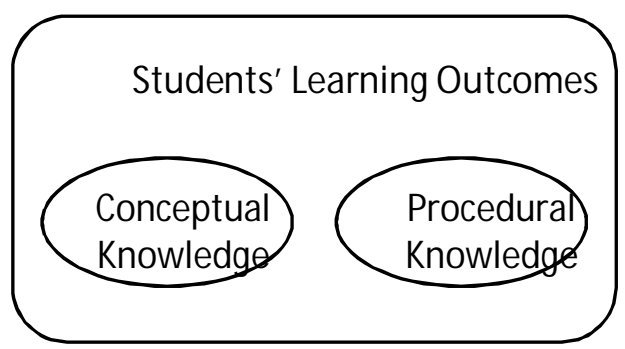

Figure 5: A framework for transferring an innovation across two different national educational settings

The two partners stressed the idea of "innovative characteristics." The results revealed that three of the four features required from the project were innovative for both educational settings (a fundamental property of materials, namely, density and FS phenomena, the use of models and modeling activities, and the use of ICT) while the inquiry approach to learning was innovative only in the Greek case (Table 6). The recognition of what is innovative for each national partner was recognized as a crucial factor for the design and development of both TLSs since it is strongly related to the autonomy and responsibility of teachers as well as the students' engagement in these innovations (human factor). There were two major challenges to be faced by the Greek group: (i) the limited autonomy and responsibility of the primary teacher (Table 1) and (ii) students' inexperience in inquiry environments. So, they decided to give detailed guidelines to the primary teacher as well as to adapt a scaffolding approach to inquiry learning tasks (Table 7). At the same time, the Finnish group followed its traditional, national method, namely the primary teacher was completely at liberty to modify the initial TLS ${ }_{1}$ within the local educational setting. As a result, the revised $\mathrm{TLS}_{3}$ included different and fewer activities in the cases of inquiry as well as model tasks (Table 7). Hence, the human factor has been revealed a crucial factor to the 'feasible aspect' of transferring the innovation. 
In doing so, the researchers of the two partners gained a better understanding of students' conceptual knowledge concerning FS phenomena and the CVS strategy by comparing their answers to the related tasks (Tables $2 \& 3$ ); while the achievement of models and modeling learning were assessed only in the case of $\mathrm{TLS}_{2}$ intervention. The above outcomes bring to light that the feasible aspect clearly affected the useful since the content (e.g. teaching-learning activities) of the feasible aspect determined the content (e.g. kind of research tasks) of the second (Fig. 5, arrow).

Furthermore, the results related to the second aspect of the transfer process (useful aspect), showed that before each TLS the two groups differed significantly in most of the measurements, with the Finnish group achieving higher scores in both conceptual and procedural tasks. The two TLSs helped both groups to improve their understanding in most of the tasks. The Greek participants benefited more from the intervention than the Finnish Group. After the intervention, the difference in conceptual and procedural understanding between the two groups either diminished or even disappeared. In other words, the two groups followed similar paths to achieve the goals of the TLS. This evidence allows us to claim that the cognitive paths that bring about this success are independent of the educational history of the group; the two groups were initially found at a different point of the same learning path.

To conclude, we argue that this educational transfer was implemented successfully in both aspects, namely the feasible and the useful aspect. The versatile communication between the two groups was the key point of this achievement. During the design process, there were four general project meetings where the partners of the groups were discussing the aims of the TLSs, teachers and student material. Moreover, they were discussing the challenges and success in the trial implementations. Several e-mails during the design of the TLSs and the translation were exchanged. During the implementation of the TLSs, there were visits to 
Greece and Finland. The representatives of the two groups, including one teacher, participated in the implementation. Reflective discussion about what was important in the implementation and about the flexibility was carried out. It is worth studying the contribution of the steering committee that facilitated an integrated view of the human parameter in relation to the feasible aspect. In accordance with the literature (Elton, 2003), this actual transfer had a basic feature: the strong interaction among all members of the two partnerships from the first invention of $\mathrm{TLS}_{2}$ to the last revision of the $\mathrm{TLS}_{3}$.

Last but not least, in this paper we draw attention to put forward specific recommendations for the successful transfer of inquiry TLSs from one educational setting to another, overcoming some obstacles (section 1). Underpinning this goal, we tried to formulate a specific framework pinpointing a part of this complex enterprise. In this type of transfer, the two teachers were experienced in teaching science. However, they have different professional profile concerning their autonomy, responsibility and implementing open inquiry learning environments. So, we consider that each teacher's profile restrains the above recommendations of the feasible aspect. Moreover, through recognizing these feasible and the useful aspect the differences in education context could be overcome. Furthermore, drawing more insights from the useful aspect, there is value in studying the change in teachers' conceptions concerning teaching and learning as well as their confidence in managing the transfer of an innovation (Pinto, 2005; Rogers, 2003). 


\section{References}

Alexandrou, A., Field, K. and Mitchell, H., (Eds.). (2005). The Continuing Professional Development of educators: emerging European issues. Oxford, UK: Symposium Books.

Author et colleagues (2003). Research in Science Education.

Authors \& colleagues (2010). ESERA Proceedings, Contemporary Science Education Research: Learning and Assessment.

Authors (2008). In: C. P. Constantinou and N. Papadouris (Eds.), Girep International Conference, Physics Curriculum Design, Development and Validation, Selected Papers. Authors (2009). Journal of Research in Science Teaching.

Authors (2013). Science Education International.

Authors (2016). In: D. Psillos and P. Kariotoglou (Eds.), Iterative Desing of Teaching-Learning Sequence.

Autio, E. \& Laamanen, T. (1995). Measurement and evaluation of technology transfer: review of technology transfer mechanisms and indicators. International Journal of Technology Management, 10(7-8), 643-664.

Boudreaux, A., Shaffer, P., Heron, P., \& McDermott, L. (2008). Student understanding of control of variables: Deciding whether or not a variable influences the behavior of a system. American Journal of Physics, 76(2), 163-170. doi:10.1119/1.2805235

Chen, Z. \& Klahr, D. (1999). All Other Things Being Equal: Acquisition and Transfer of the Control of Variables Strategy. Child Development, 70(5), 1098-1120.

Cobb, P., Confrey, J., DiSessa, A., Lehrer, R., \& Schauble, L. (2003). Design experiments in educational research. Educational Researcher, 32(1), 9-13.

Darr, E., D. \& Kurtzberg, T., R. (2000). An Investigation of Partner Similarity Dimensions on Knowledge Transfer. Organizational Behavior and Human Decision Processes, 82(1), 2844.

Deci, E. L., \& Ryan, R. M. (2004). Handbook of self-determination research. Rochester, NY: The University of Rochester Press.

Elton, L. (2003). Disseminations of Innovations in Higher Education: A Change Theory Approach. Tertiary Education and Management, 9(3), 199-214.

Enders, J. (2005). Border crossings: Research training, knowledge dissemination and the transformation of academic work. Higher Education, 49, 119-133.

EACEA/Eurydice (2008). Levels of Autonomy and Responsibilities of Teachers in Europe. Brussels:Eurydice.

EACEA/Eurydice (2011). Science Education in Europe: National Policies, Practices, and Research. Brussels:Eurydice.

Fullan, M. (2007). The New Meaning of Educational Change (4 ${ }^{\text {th }}$ ed.). New York: Teachers College Press.

Gagnon, M., L. (2011). Moving knowledge to action through dissemination and exchange. Journal of Clinical Epidemiology, 64, 25-31.

Goh, S., G, (1997). Managing effective knowledge transfer: an integrative framework and some practice implications. Journal of Knowledge Management, 6(1), 23-30.

Greenhouse, S., W., \& Geiser, S. (1959). On methods in the analysis of profile data. Psychometrica, 4, 95-12.

Havu-Nuutinen, S. (2005). Examining young children's conceptual change process in floating and sinking from a social constructivist perspective. International Journal of Science Education, 27(3), 259-279.

Hsieh, H. \& Shanon, S. (2005). Three Approaches to Qualitative Content Analysis. Qualitative Health Research, 15(9), 1277-1288. 
Hutchinson, R., J., \& Huberman, M. (1994). Knowledge Dissemination and Use in Science and Mathematics Education: A Literature Review. Journal of Science Education and Technology, $3(1), 27-47$.

Justi, R. \& Gilbert, J. K. (2002). Science teachers' knowledge about and attitudes towards the use of models and modeling in learning science. International Journal of Science Education, 24(12), 1273-1292. doi:10.1080/09500690210163198

Lijnse, P. L. (1995). Developmental Research' as a way to an empirically based didactical structure of science. Science Education, 79 (2), 189-199.

Matthews, M. R., (2007). Models in Science and in Science Education: An Introduction. Science \& Education. 16, 647-652.

Organisation for Economic Co-operation and Development (OECD) (2010). PISA 2009 Results: What Students Know and Can Do - Student Performance in Reading, Mathematics and Science, (Volume I). Paris: OECD Publishing.

Perkins, D., N., \& Grotzer, T., A. (2005). Dimensions of causal understanding: the role of complex causal models in students' understanding of science. Studies in Science Education, 41, 117-166. doi:10.1080/03057260508560216

Pinto, R. (2005). Introducing Curriculum Innovations in Science: Identifying Teachers' Transformations and the Design of Related Teacher Education. Science Education, 89, 1-12.

Rocard, M. (2007). Science Education NOW: A renewed Pedagogy for the Future of Europe, Brussels: European Commission. Retrieved from: http://ec.europa.eu/research/sciencesociety/document_library/pdf_06/report-rocard-onscience- education_en.pdf.

Rogers, E., M. (2003). Diffusion of Innovations ( $5^{\text {th }}$ ed.). New York: Free Press.

Smith, C., Snir, J., \& Grosslight, L. (1992). Using Conceptual Models to Facilitate Conceptual Change: The Case of Weight-Density Differentiation, Cognition and Instruction, 9(3), 221283. doi:10.1207/s1532690xci0903_3

Song, M., Berends, van der Bij, H. H., \& Weggeman, M. (2007). The Effect of IT and Colocation on Knowledge Dissemination. The Journal of Product Innovation Management, 24, 52-68.

Straus, E., S., Tetroe, M., J., Graham, D., I. (2011). Knowledge translation is the use of knowledge in health care decision making. Journal of Clinical Epidemiology, 64, 6-10.

Strauss, A., \& Corbin, J. (1994). Grounded theory methodology: An overview. In N. Denzin \& Y. Lincoln (Eds.), Handbook of qualitative research (pp. 273-285). Thousand Oaks, CA: Sage.

Tiberghien, A., Vince, J. \& Gaidioz, P. (2009). Design-based Research: Case of a teaching sequence on mechanics International Journal of Science Education, 31(17), 2275-2314.

Treagust, D. F., Chittleborough, G., \& Mamiala, L. T. (2002). Students' understanding of the role of scientific models in learning science. International Journal of Science Education, 24, 357-368. doi:10.1080/09500690110066485

Vosniadou, S. (2010). Instructional considerations in the use of external representations. In L. Verschaffel, E. de Corte, T. de Jong, \& J. Elen (Eds.), Use of representations in reasoning and problem solving (pp. 36-54). New York: Routledge. 